\title{
Erratum to: Stress examination of flexor tendon pulley rupture in the crimp grip position: a 1.5-Tesla MRI cadaver study
}

\author{
Thomas Bayer • Simon Fries • Andreas Schweizer • \\ Isabelle Schöffl • Rolf Janka • Georg Bongartz
}

Published online: 28 October 2014

(C) ISS 2014

\section{Erratum to: Skeletal Radiol}

DOI 10.1007/s00256-014-2002-7

The original version of this article unfortunately contained error. Figure 3 was incorrectly captured, the correct Fig. 3 is shown below:

The online version of the original article can be found at http://dx.doi.org/ 10.1007/s00256-014-2002-7.

T. Bayer $(\bowtie) \cdot$ R. Janka

Department of Radiology, University of Erlangen-Nuremberg,

Maximiliansplatz 1, 91054 Erlangen, Germany

e-mail: thomas.bayer@uk-erlangen.de

\section{S. Fries}

Orthopaedic Department, Cantonal Hospital Lucerne, Wolhusen,

Switzerland

\author{
A. Schweizer \\ Department of Orthopaedics, Balgrist, University of Zurich, Zurich, \\ Switzerland \\ I. Schöffl \\ Department of Pediatrics, Klinikum Bamberg, Bamberg, Germany \\ G. Bongartz \\ Department of Radiology, University Basel, Basel, Switzerland
}




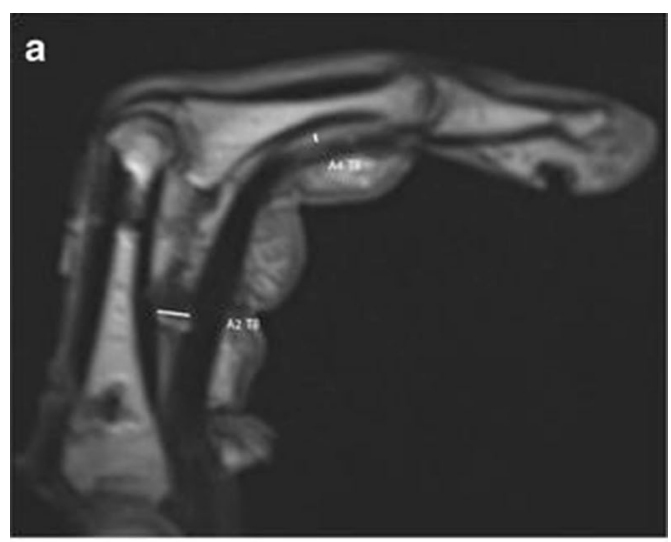

b

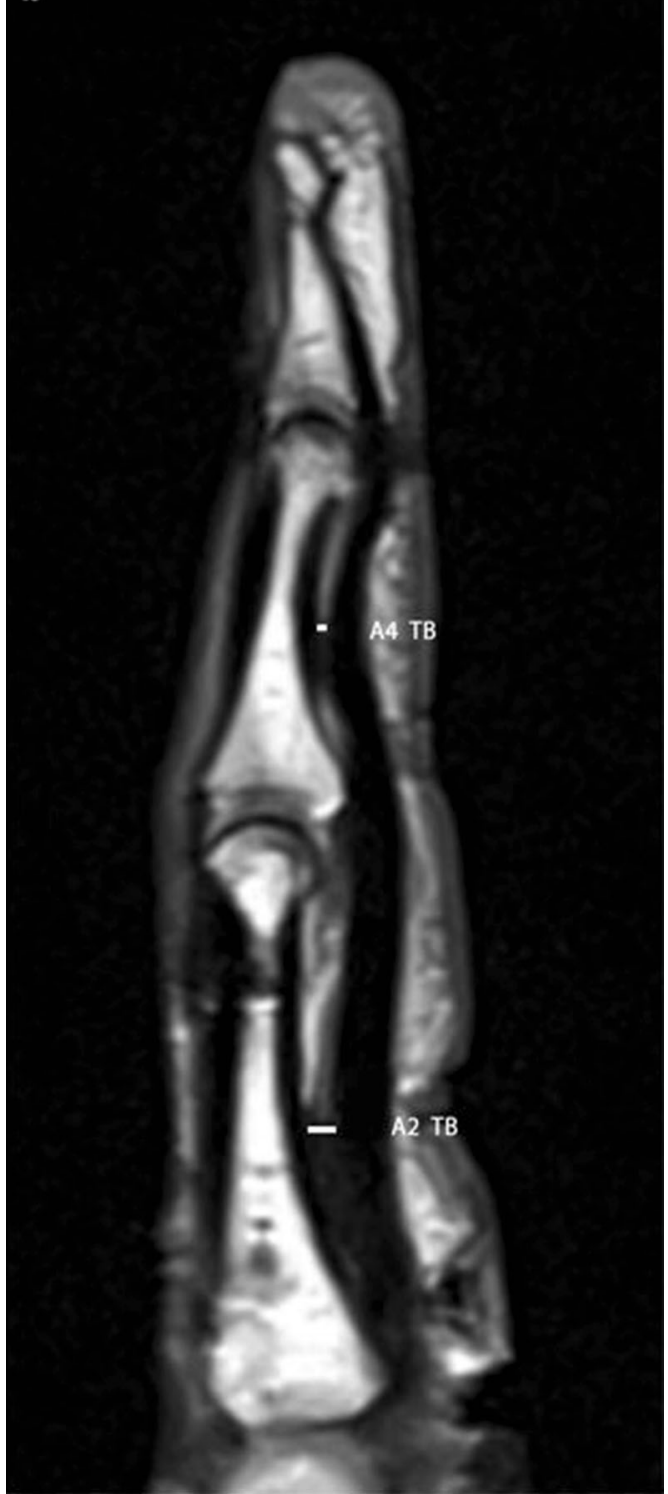

Fig. 3 Single A2 pulley rupture a in the crimp grip position and $\mathbf{b}$ in the neutral position. $\mathrm{A} 2$ tendon bone distance $(A 2 T B)$ is augmented to $3.6 \mathrm{~mm}$ in the crimp grip position in comparison to $2.1 \mathrm{~mm}$ in the neutral position. A4 tendon bone distance $(A 4 T B)$ is not augmented 